\title{
A Rare Case of Severely Acute Collum Angle in Orthodontic Practice - A Case Report
}

\author{
Harshil Naresh Joshi i*, Jay Sureshkumar Soni ${ }^{2}$, Manjot Kaur ${ }^{3}$, \\ Rameshwar H Taluja ${ }^{4}$, Swetha Taluja ${ }^{5}$ and Shireen Mann ${ }^{6}$ \\ ${ }^{1}$ K.M. Shah Dental College and hospital, Sumandeep Vidyapeeth, \\ Pipariya Waghodia, Vadodara, Gujarat, India. \\ ${ }^{2}$ Ahmedabad Dental College \& Hospital, Ahmedabad, Gujarat, India \\ ${ }^{3}$ BDSBaba Jaswant Singh Dental College \&t Hospital, Punjab, India \\ ${ }^{4} B D S, M D S$ (Prosthodontist and Implantologist) \\ ${ }^{5} B D S$, PGCOI (Dental Surgeon) \\ ${ }^{6}$ BDS, Nation Dental College and Hospital, Punjab, India Corresponding author email: drharshiljoshi11@gmail.com
}

\section{ABSTRACT}

The collum angle is an angular measurement of the difference between the longitudinal axis of the crown and the longitudinal axis of the root. This is unusual case of the acute collum angle. Anterior cross bite is relatively a common presentation. In most cases, single or multiple tooth are involved. This article describes the rare case of 15 year old boy with the acute collum angle. The steps require for thorough diagnosis is elaborated. Attention must be given to root proximity to the cortical plate. Extrusive, intrusive and torquing forces must be carefully examined in teeth with large collum angles.

\section{KEY WORDS: COLLUM ANGLE, ANTERIOR BITE, CORTICAL PLATE.}

\section{INTRODUCTION}

Variability in tooth morphology is an important consideration in the attainment of an aesthetic, functional, and optimal occlusion of teeth. The angulations of the root to the crown, particularly of the single-rooted anterior teeth are known as collum angle (Bryant et al., 1984; Delivanis and Kuftinec, 1980). (Fig.1) Collum angle is the angle formed by the intersection of the long axis of the crown and root using the lateral cephalogram. Though the lateral cephalogram represents, the 2D image of the 3D object contralateral side is superimposed. In cases with the anterior crossbite(Single Or multi-tooth) at most care should be taken to diagnose for the root morphology. In cases with the Crown to root angulation of maxillary central incisors may limit the degree to which the roots of these teeth can be torqued lingually when related to the maxillary lingual cortical plate of bone (McIntyre GT and Millett, 2003; Harris et al., 1993).

Biosc Biotech Res Comm P-ISSN: 0974-6455 E-ISSN: 2321-4007

\section{rossef}

Identifiers and Pagination

Year: 2021 Vol: 14 No (6) Special Issue

Pages: 25-28

This is an open access article under Creative

Commons License Attribn 4.0 Intl (CC-BY).

DOI: $h$ ttp://dx.doi.org/10.21786/bbrc/14.6.5
Deviant root angulation confounds intended axial loads for intrusion and extrusion and may cause the root to encroach on the labial or lingual cortical plate when repositioned. Variations in collum angle of the maxillary central incisors can affect the treatment, the prognosis, or the stability of orthodontic therapy. According to Taylor (1969), the relation of the root to the crown varies considerably because both are subject to variations in curvature \&t environment. The Collum angle (Fig.1) can be defined as a crown root supplementary angle of maxillary central incisors. The present case represents the extremity of the single tooth crossbite with an obtuse collum angle. Anterior crossbite is a malocclusion in which one or more of the maxillary anterior teeth occlude palatally to the mandibular incisors. If it occurs due to the palatal malposition of a maxillary tooth with associated labioversion of contacting mandibular teeth, then it is called a dental crossbite (Pai et al., 2017; Jain et al., 2017).

Trauma to the primary incisor with a displacement of the permanent tooth bud, supernumerary anterior teeth, odontomas, crowded incisors, and delayed exfoliation of the primary incisors are the common etiological factors for this condition (Shailaja et al., 2016). Several treatments

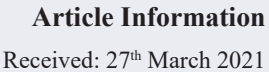

ccepted after revision: $24^{\text {th }}$ May 2021 
have been applied for the correction of anterior crossbite (Wang et al., 2019; Naini et al., 2019).

The appliance needed for the correction of crossbite should be comfortable and easily tolerated. Early correction of this malocclusion will prevent further complications. But to correct single tooth crossbite is not easy always. Here we have a case having a single tooth (11) crossbite with well-aligned arches. The pivotal role for the collum angle comes here. On taking OPG the root morphology of the central incisor is not visible due to the focal drum area. Though the root morphology wasn't visible, the operator further went for СВCT. Surprising results were found. The simple showing single tooth crossbite shows an extreme obtuse collum angle of more than $90^{\circ}$. (Fig 2,3,4) The average value of the Collum angle was $6.1^{\circ} \pm 5.2^{\circ}$ for class-I malocclusions, $5.3^{\circ} \pm$ $4.2^{\circ}$ for class-II division-I malocclusions, $10.6^{\circ} \pm 4.4^{\circ}$ for class-II division-2 malocclusions, and $5.6^{\circ} \pm 5.1^{\circ}$ for class-III malocclusions.

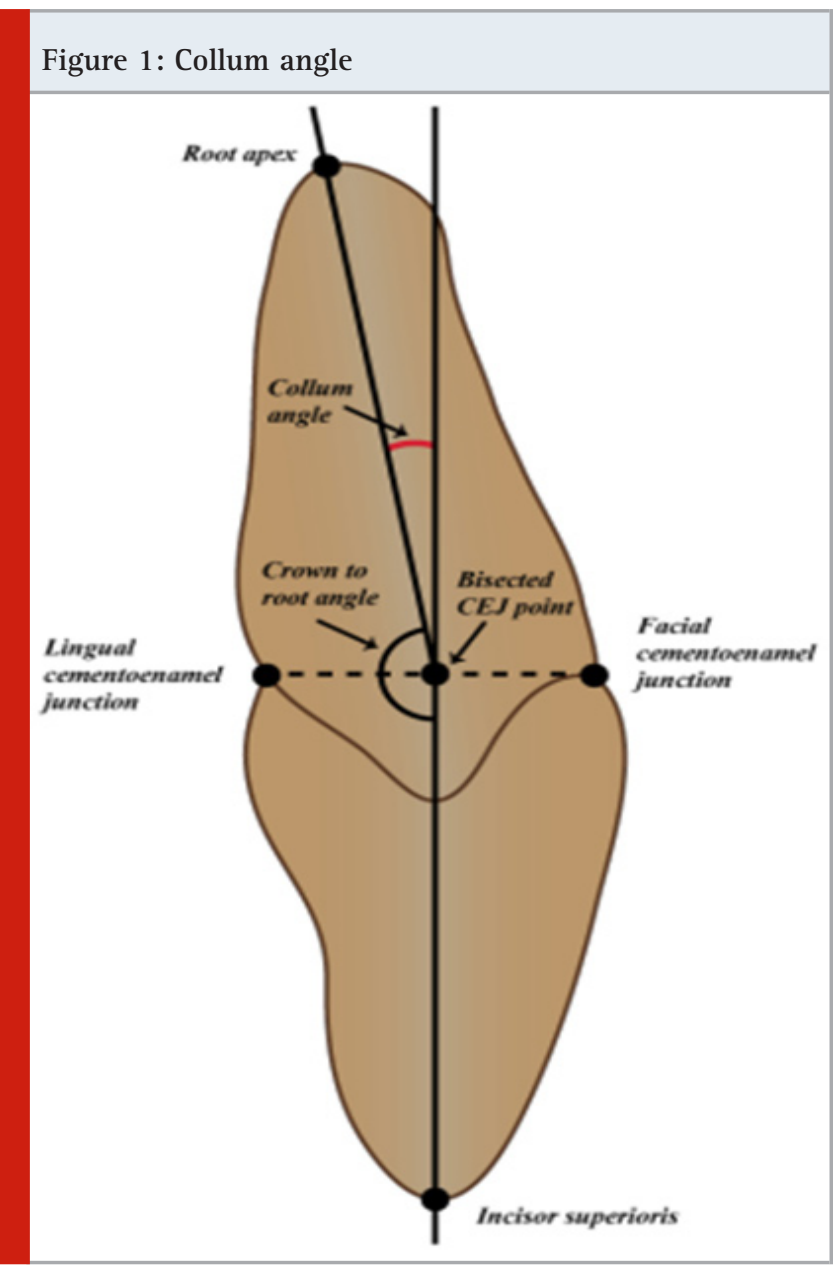

The Collum Angle in Orthodontics: When Dr. Lawrence Andrews designed the first fully programmable brackets, he revolutionized the field of orthodontics. This development was based on the Six Keys of Normal Occlusion, in which he named crown inclination as the third key (Andrews and Straight Wire, 1989). Although the importance of crown inclination was widely discussed, no mention of the crown to the root was made in the "Six Keys of Normal Occlusion"). This omission may have subsequently, propagated the assumption that the longitudinal axis of the crown and root formed a straight line (Harris et al., 1993). The aforementioned concept is especially apparent in cephalometric analyses where the crown to root angulation is not evident in the maxillary incisor templates (Bryant et al., 1984). Instead, the maxillary incisor template is automatically drawn in, such that the long axis of the crown and root are identical. By doing so, the crown inclination is taken into consideration but no forethought is given to the inclination of the root and its inherent consequences.
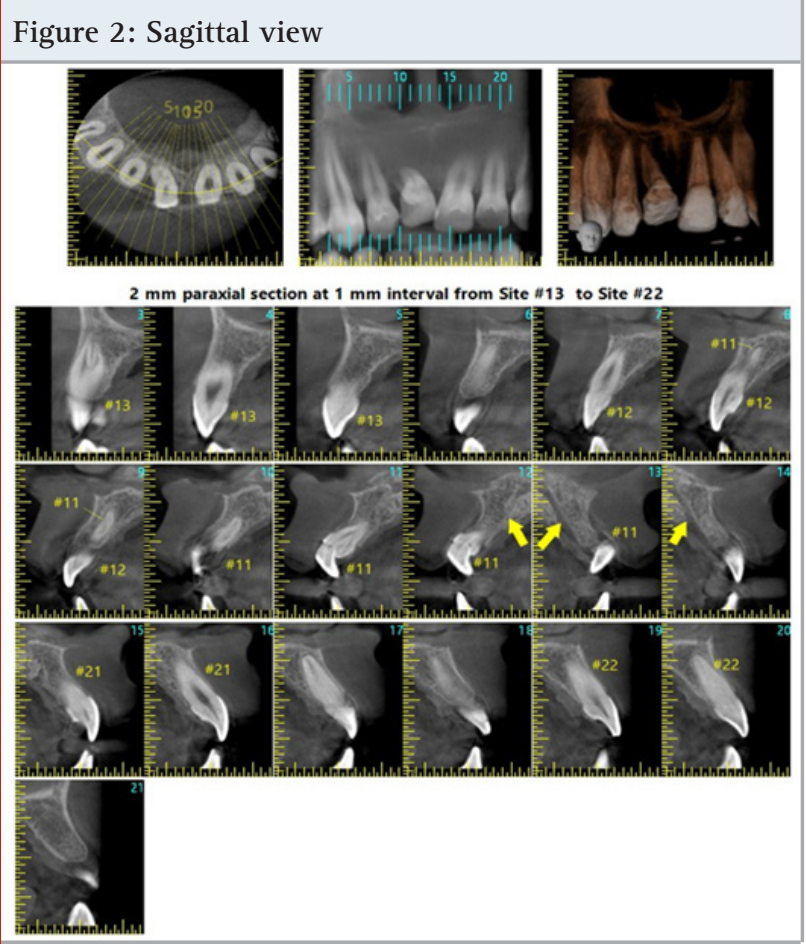

Although Andrews disregarded root inclination when developing the Straight Wire Appliance, the importance of root position is evident in the grading system developed by the American Board of Orthodontics (ABO). As the golden standard of 50 orthodontics, the $\mathrm{ABO}$ has carefully selected root position as a paradigm upon which Board Certified cases are graded upon. In assessing root position as a fundamental criterion, the $\mathrm{ABO}$ has noted its value in the treatment planning of cases. To assess crown to root angulations, the collum angle was introduced. The actual crown to root angulation was measured by quantifying the angulation between the longitudinal axis of the crown and the longitudinal axis of the root. This angle was then converted to its supplementary angle, by subtracting its value from 180 degrees. Instead of using large values that were difficult to comprehend, the collum 
angle was chosen for its ease in the directional analysis of crown inclination.

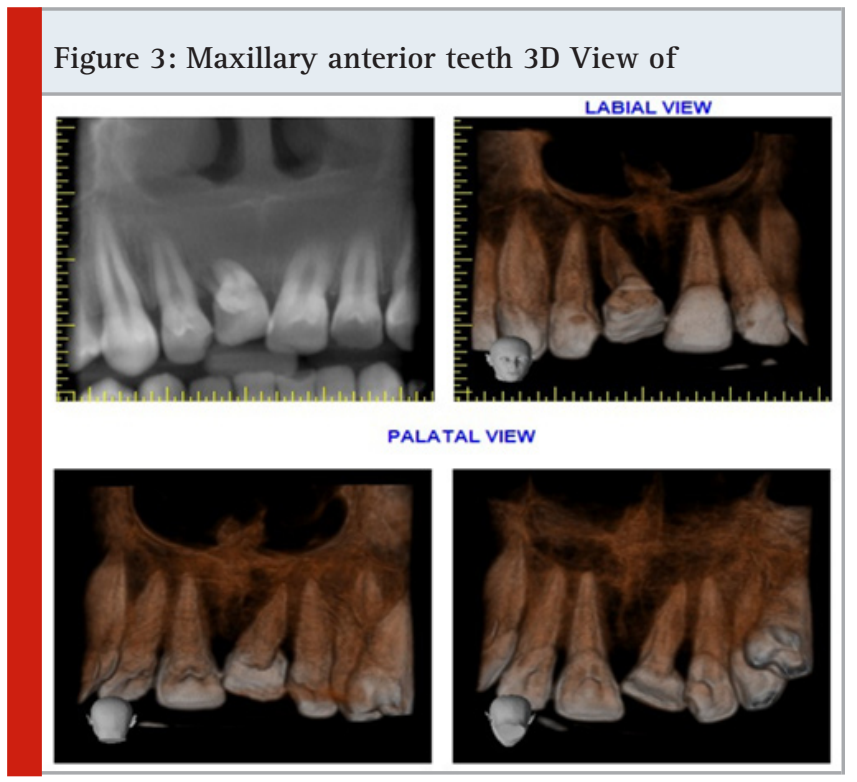

Figure 4: Axial, Coronal \&t Sagittal View
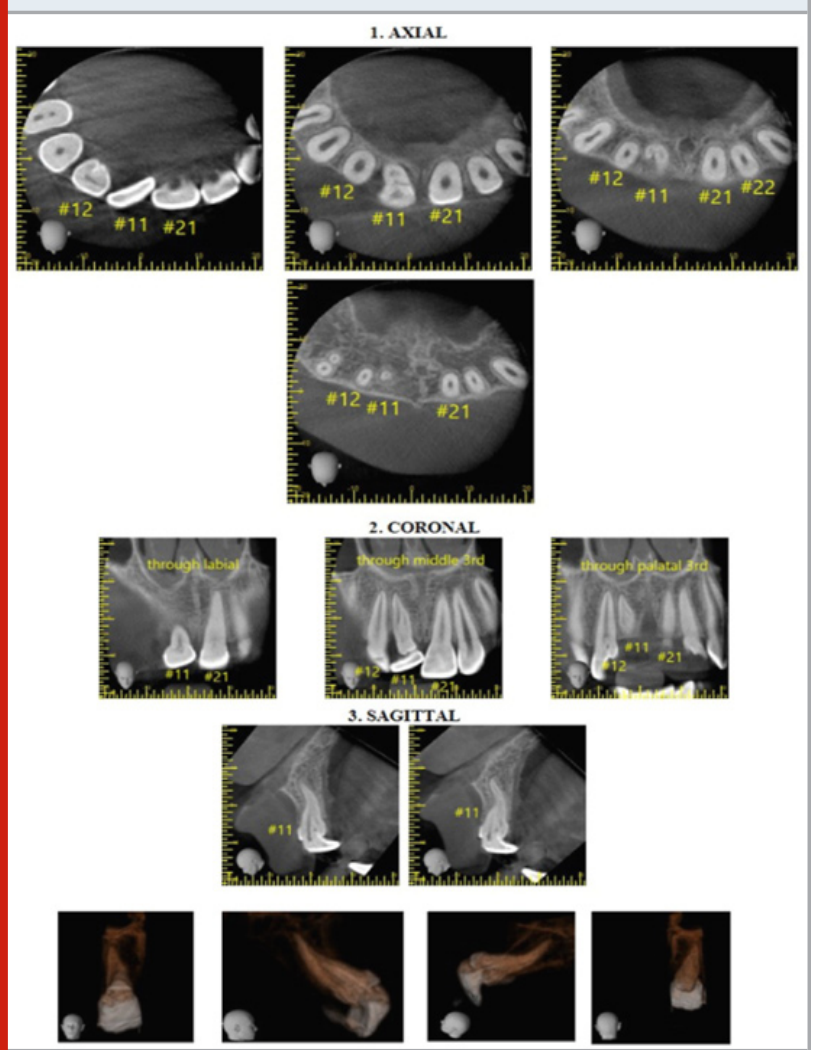

This was because the angular measurements were based on the value of zero rather than the alternative of 180 degrees. In this way, a positive value would easily define the angular measurement in the lingual direction and a negative value would indicate a labial direction of crown bending. Because of this, the crown to root inclination was measured as the collum angle, rather than the crown to root angulation. With the use of CBCT, this study was the first to quantify the collum angles of all anterior teeth. Unlike previous studies, superimposition issues with lateral cephalograms were overcome to allow for measurements of teeth adjacent to the maxillary central incisors. In addition, large numbers of extracted teeth were not necessary to measure the collum angle.

This allowed for quantification of a large volume of teeth which may have been otherwise difficult to obtain. Furthermore, the 3D rendering capabilities of CBCT technology allowed for the correct three-dimensional orientation of each tooth. This is 51 especially important in this study because the level of the CEJ changes as you shift away from the center of the tooth. Thus, if the slice used for measurement is not properly oriented, the level of the CEJ will change. This method of orientation was not possible in the lateral cephalograms used in the past. In this way, the use of СBCT technology improved the accuracy and the scope in which the measurements were made.

The Collum Angle in Dentistry: In evaluating the collum angle, it is apparent that its consequences may have several applications in dentistry. This is especially important in the anterior teeth where esthetics is a major concern. In regards to restorative dentistry, post-placement in teeth with large collum angles may cause difficulty in constructing the core. The post may be shortened to restore the crown with the proper inclination. In this way, the retention of the final restoration is reduced. In regards to periodontics, root prominence, dehiscences, and soft tissue esthetics may be affected.

This is especially apparent in teeth with negative collum angles, where the root is facially inclined to the crown axis. When placing anterior implants, the implant post is commonly placed parallel to the longitudinal axis of the previous root. However, if the previous tooth had a large collum angle, the crown must be restored as such to prevent misalignment of the restoration. This necessitates the use of an angled abutment. However, when such an abutment is used, stress is concentrated on the buccal side of the fixture, causing post-surgical tension in the gingiva (Shen, 2012)14. This may, therefore, cause a recession and other unwarranted cosmetic defects. The persistence of this post-surgical tension may even be problematic when a soft tissue graft is completed, causing the recession to return. In addition, increased abutment angulations have been shown to increase the magnitude of stress and strain in cortical bone (Clelland et al., 1995). This increase in stress generation is also seen in orthodontics with large collum angles in natural dentition. In Heravi et al., (2013) study, retraction of Class II div 2 maxillary central incisors resulted in forces that were $1.18 \mathrm{x}$ higher than in Class I maxillary incisors. However, when an intrusive force was applied, the teeth 
with larger collum angles demonstrated lower stress distribution to the periodontal ligament, (Heravi, 2013). Although the collum angle may have various effects in dentistry, its application has been most frequently discussed in regards to orthodontics.

\section{CONCLUSION}

The Collum angle in the maxillary central incisor, between the crown axis and root axis is significantly. When the collum angle is significantly greater than zero, treatment mechanics can be affected. In particular, torquing of such teeth against the cortical plate may be limited to avoid unwarranted root resorption and alveolar perforation.

\section{REFERENCES}

Andrews, L.F., 1989. Straight wire: the concept and appliance. LA Wells Company.

Bryant, R.M., Sadowsky, P.L., Dent, M. and Hazelrig, J.B., 1984. Variability in three morphologic features of the permanent maxillary central incisor. American Journal of Orthodontics, 86(1), pp.25-32.

Bryant, R.M., Sadowsky, P.L., Dent, M. and Hazelrig, J.B., 1984. Variability in three morphologic features of the permanent maxillary central incisor. American Journal of Orthodontics, 86(1), pp.25-32.

Clelland, N.L., Lee, J.K., Bimbenet, O.C. and Brantley, W.A., 1995. A three-dimensional finite element stress analysis of angled abutments for an implant placed in the anterior maxilla. Journal of prosthodontics, 4(2), pp.95-100.

Delivanis, H.P. and Kuftinec, M.M., 1980. Variation in morphology of the maxillary central incisors found in class II, division 2 malocclusions. American journal of orthodontics, 78(4), pp.438-443.

Harris, E.F., Hassankiadeh, S. and Harris, J.T., 1993. Maxillary incisor crown-root relationships in different angle malocclusions. American Journal of Orthodontics and Dentofacial Orthopedics, 103(1), pp.48-53.

Harris, E.F., Hassankiadeh, S. and Harris, J.T., 1993. Maxillary incisor crown-root relationships in different angle malocclusions. American Journal of Orthodontics and Dentofacial Orthopedics, 103(1), pp.48-53.

Heravi, F., Salari, S., Tanbakuchi, B., Loh, S. and
Amiri, M., 2013. Effects of crown-root angle on stress distribution in the maxillary central incisors' PDL during application of intrusive and retraction forces: a three-dimensional finite element analysis. Progress in orthodontics, 14(1), pp.1-10.

Jain, M., Vyas, M. and Singh, J.R., 2017. Effect of crown angulation of maxillary incisor on effective arch perimeter. Journal of clinical and diagnostic research: JCDR, 11(6), p.ZC92.

Latchoumi, T.P., Ezhilarasi, T.P. and Balamurugan, K., 2019. Bio-inspired weighed quantum particle swarm optimization and smooth support vector machine ensembles for identification of abnormalities in medical data. SN Applied Sciences, 1(10), pp.1-10.

McIntyre, G.T. and Millett, D.T., 2003. Crown-root shape of the permanent maxillary central incisor. The Angle Orthodontist, 73(6), pp.710-715.

Naini, F.B., Manouchehri, S., Al-Bitar, Z.B., Gill, D.S., Garagiola, U. and Wertheim, D., 2019. The maxillary incisor labial face tangent: clinical evaluation of maxillary incisor inclination in profile smiling view and idealized aesthetics. Maxillofacial plastic and reconstructive surgery, 41(1), pp.1-7.

Pai, S.S., Panda, S., Pai, V., Anandu, M., Vishwanath, E. and Suhas, A.S., 2017. Effects of labial and lingual retraction and intrusion force on maxillary central incisor with varying collum angles: A three-dimensional finite elemental analysis. Journal of Indian Orthodontic Society, 51(1), pp.28-37.

Shailaja, A.M., Gowda, N.C. and Gowda, S., 2016. The collum angle of Maxillary Central Incisors in different skeletal malocclusions-A Cephaometric study. Int J Applied Dental Sci, 2(03), pp.33-36.

Shen, Y.W., Hsu, J.T., Wang, Y.H., Huang, H.L. and Fuh, L.J., 2012. The Collum angle of the maxillary central incisors in patients with different types of malocclusion. Journal of dental sciences, 7(1), pp.72-76.

Taylor, R.M.S., 1969. Variation in form of human teeth: I. An anthropologic and forensic study of maxillary incisors. Journal of dental research, 48(1), pp.5-16.

Wang, X.M., Ma, L.Z., Wang, J. and Xue, H., 2019. The crown-root morphology of central incisors in different skeletal malocclusions assessed with cone-beam computed tomography. Progress in orthodontics, 20(1), pp.1-11. 